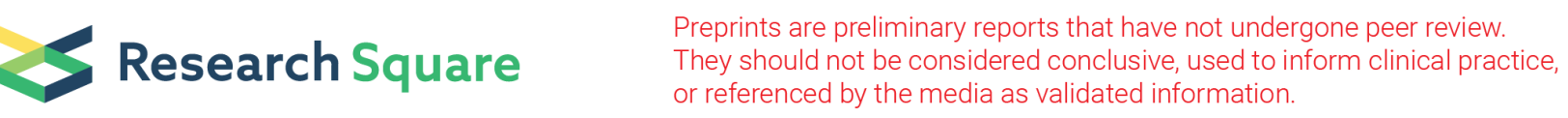

\title{
A long term condition / disability, loneliness, and social isolation are associated with lower quality of life, but a sense of coherence buffers the adverse effects: a cross sectional study in older people
}

Hugo van Woerden ( $\sim$ hugo.vanwoerden@uhi.ac.uk)

University of the Highlands and Islands

Neil J. Angus

University of the Highlands and Islands

Vasiliki Kiparoglou

Leeds Biomedical Research Centre, Oxford

lain Maitland Atherton

Edinburgh Napier University

Janni Leung

University of Queensland

Research article

Keywords: Ioneliness, social isolation, disability, rurality, quality of life

Posted Date: January 6th, 2020

DOI: https://doi.org/10.21203/rs.2.20085/v1

License: (c) (i) This work is licensed under a Creative Commons Attribution 4.0 International License. Read Full License 


\section{Abstract}

\section{Background}

The impact of disability, long term conditions, rurality, living alone, and being a carer on health has some evidence base. The extent to which a strong sense of coherence, a factor hypothesised to promote wellbeing, may moderate these associations is unknown. A model of physical, environmental and social factors on quality of life was tested, with particular emphasis on whether a strong sense of coherence (SoC) buffered these determinants of quality of life.

Methods

A cross sectional postal survey was undertaken of a random sample of 3,000 individuals over 65 years, across a rural population. Physical, environmental, and psychological variables were assessed against quality of life using ANOVA and a generalised linear model including the interaction effects of SoC.

Results

Of 1,547 responses, 1,471 were analysable and provided permission for research use. ANOVA demonstrated that age, gender, long-term condition / disability (LTC-D), living alone, $>20$ hours unpaid care for others per week, SoC, and loneliness, were associated with lower quality of life $(p<0.01)$. There were strong correlations $(p>0.01)$, between age and LTC-D, living alone, and poor SoC. Living alone was correlated with emotional and social loneliness; but those with higher SoC were less likely to experience loneliness. In an adjusted generalised linear model, significant associations with a lower quality of life were observed from: LTC-D, emotional loneliness and social loneliness $(B=-0.44,-0.30$, and -0.39 , respectively, all $p<0.001)$. The only interaction with SoC that was statistically significant (at $p<0.05$ ) was LTC-D. A stronger sense of coherence buffered the negative effects of long-term condition / disability on quality of life.

\section{Conclusions}

This study is novel in examining the relationship between the presence of a LTC-D and loneliness in an older rural population. The physical, environmental and social factors examined, identified long-term conditions / disability and loneliness to be the strongest factors associated with quality of life. SoC somewhat buffered the adverse effect of LTC-D on quality of life, but did not do so for loneliness. Future research to understand what could be done to improve quality of life in a rural context is warranted.

\section{Introduction}

A significant proportion of older people suffer from a long term condition / disability. This issue is of significant policy interest, as there is increasing recognition that there is a need to understand the different factors that contribute to quality of life in this population. Loneliness is an important potential factor in this context [1], but quality of life in older populations is affect by a wide range of other factors including social isolation [2], disability [3], long term conditions [4], living alone, or being a carer [5]. Rurality is another factor that may be associated with poorer health outcomes [6], but the picture is complicated, as there is also evidence that rural communities can provide each other with greater support [7]. Relatively little research has been undertaken to understand the interactions between these factors and they have therefore been incorporated in this study.

Measuring 'quality of life' as an outcome is complex, and it should be acknowledged that simplistic assumptions that a long term condition / disability inevitably leads to a poor quality of life is incorrect [8]. This may be because the components that constitute quality of life reflect changing life goals, and an inherent capacity to adjust to loss during the life course. Quality of life in the presence of a long term condition / disability may also be influenced by factors such as a sense of meaning, purpose, and a sense of being valued, which are incorporated in the model underpinning salutogenesis [9].

The capacity to cope in the face of adversity was studied by Antonovsky, who investigated holocaust survivors after the Second World War, and sought to understand the characteristics that had been most significant in those who survived [10]. He 
characterised these factors as 'salutogenic', and emphasised the importance of a personal sense of coherence.

A sense of coherence may be defined as, "The extent to which one has a pervasive, enduring though dynamic, feeling of confidence that one's environment is predictable and that things will work out as well as can reasonably be expected” [11, 12]. Antonovsky suggested that sense of coherence is composed of three factors: comprehensibility, manageability, and meaningfulness. Expressed in greater detail, "comprehensibility is the extent to which events are perceived as making logical sense, that they are ordered, consistent, and structured. Manageability is the extent to which a person feels they can cope. Meaningfulness is how much one feels that life makes sense, and challenges are worthy of commitment" [13].

There are a wide range of concepts that overlap with sense of coherence including mastery, resilience and hardiness [14]. However, the concept of a sense of coherence has stood the test of time and has therefore been used in this paper. A range of studies have demonstrated that sense of coherence can have main, moderating, and mediating effects on health and quality of life [15], and this project therefore sought to assess any buffering effect that a sense of coherence might have on associations with quality of life, in the context of a population survey.

Population surveys need to be kept short to improve completion rates. It is therefore welcome that the original 29 item sense of coherence scale was later reduced to 13 items [16] and has more recently been reduced to a three item scale [17]. The three item sense of coherence scale has consequently been used in this study.

The geographical context for this study, NHS Highland, is very rural. NHS has a low population density, covering $41 \%$ of the land mass of Scotland, but with only a population of 320,000 . There is one small city, a number of market towns, many small towns and villages, and 26 inhabited islands. The effect of rurality on the interplay between different factors affecting quality of life was therefore of interest to this study. Measuring rurality in Scotland is generally undertaken using an eight, six or three category index. For the purposes of this study, the index was collapsed into three categories, which is standard practice for this index [18].

The impact of disability, long term conditions, rurality, living alone, and being a carer on health has some evidence base, however, the extent to which these factors might be buffered by a strong SoC is unknown. To explore this, we hypothesised a model of physical, environmental and social factors, and sought to examine whether SOC buffers any of these factors, in terms of their impact on quality of life, in the context of older people (65+) in a rural Scottish Health Board (Fig. 1).

\section{Methods}

\section{Study design}

A cross-sectional survey was undertaken of a random sample of 3,000 households across a defined area of the north of Scotland (NHS Highland). The survey sample frame was drawn from the set of all patients registered with GP practices within the health board, where there was known to be at least one individual in the household over 65 years. The sample size was designed to be adequate to identify differences in characteristics in relevant sub-groups. A questionnaire was drawn up which included the De Jong-Gierveld loneliness scale [19], the three item sense of coherence scale [17, 20], demographic data, and a single item quality of life question, "How is your quality of life?" with responses, excellent, good, fair, poor, very poor [21]. This was posted with a reply envelope. A single reminder was also sent. We asked that the questionnaire be completed by or on behalf of the oldest member of the household.

\section{Participants}

Participants had a mean age of 74.4 (SD=7.01). From the 3,000 surveys issued, 1,547 were returned, a response rate of $51.6 \%$. Sixty-five responses were excluded due to consent for research purposes being withheld, and a further 11 were excluded due to missing data on the quality of life question (our key outcome measure). The final sample size for this study was $N=1,471$ (see flow chart in Figure 2). 


\section{Variables}

Physical variables examined included age (10-year age intervals ), gender, and long-term condition / disability (yes or no). Environmental variables examined included rurality ('other urban areas'; 'small towns, accessible rural, or remote rural'; 'very remote rural'), living alone, and being a carer for others ('no or <20 hours'; 'yes 20 hourst'). Psychological variables examined included sense of coherence (classed as 'weak' (scores 6-9), 'intermediate' (scores 4-5) and 'strong' (score 3 or less), and three Ioneliness scales - 'emotional loneliness', 'social loneliness' and 'overall loneliness' (in each loneliness scale scores >1 SD above the mean were categorised as 'high'). Quality of life (scored 1-5, from very poor to excellent) was used as the outcome variable.

\section{Statistical analysis}

Descriptive statistics analysis was undertaken and the pattern of missing data in participants was examined. Missing data were below $5 \%$ for the physical and environmental factors, and sense of coherence (see Supplementary Material Appendix A). However, there was a higher level of missing data for the loneliness scales, ranging from $22.9 \%-29.8 \%$, due to the absence of at least one answer to the six relevant answers making up the three scales for 'social loneliness' (3 questions), 'emotional loneliness' (3 questions) and 'overall loneliness' (combined 6 questions).

On the basis of our understanding of the literature, we would assume that participants with higher levels of loneliness were less likely to respond, and hence the data would be biased towards underestimating loneliness. To address this potential bias from missing data across the loneliness scales, missing data analyses were conducted. Missing data in the loneliness scales were associated with older age $(p<0.001)$, female gender $(p=0.012)$, disability $(p<0.001)$, living alone $(p=0.001)$, and lower quality of life $(p=0.006)$. We also compared levels of loneliness in the baseline data set, against the data set including imputed values, where multiple imputation was used to impute missing values drawing on all the variables of interest in our a priori defined model. In confirmation of our assumption, levels of loneliness were lower in the baseline data set than in the imputed data set. Based on this finding, multiple imputation was used for the analysis presented in this paper.

Bivariate associations between 'quality of life' and physical, environmental, and psychological variables were examined by conducting ANOVAs for categorical variables. A correlation matrix was used to examine collinearity among physical, environmental, and psychological variables.

The main analysis for this paper was a generalised linear model with the physical, environmental, and psychological variables as the exposure variables, and 'quality of life' as the outcome. The model included testing for interaction effects between physical, environmental, and psychological exposure variables and 'sense of coherence' in relation to the outcome of 'quality of life' (see Figure 1 for conceptual model).

\section{Results}

\section{Descriptive statistics and characteristics of sample}

There was a spread of age and gender across participants, with about half in the 70-79 age group, and half in each sex (see Table 1). Over half had a long-term condition / disability. Proportions of participants by rurality of residence were: $21.5 \%$ living in 'other urban areas'; $42.4 \%$ in 'small towns, accessible rural, and remote rural'; and $36 \%$ in 'very remote rural areas'. Seventy percent of the participants were not living alone, and $6.6 \%$ of participants provided 20 hours or more per week of unpaid care for others. Overall, participants reported moderate levels of sense of coherence, and moderately high levels of quality of life. Approximately $20 \%$ reported high levels of loneliness.

\section{Bivariate associations with quality of life}


Lower levels of quality of life were significantly associated with older age, female gender, having a long-term condition / disability, living alone, providing unpaid care for others for 20 hours or more per week, low sense of coherence, and high levels of loneliness (see Table 2). Quality of life did not differ by level of rurality.

\section{Inter-correlation between exposure variables}

Inter-correlation between exposures were moderate for the loneliness scales, and very low to moderately low for all other variables (see Table 3). Sense of coherence was negatively associated with age, long-term condition/ disability, unpaid care for others of 20+ hours per week, and loneliness, but positively associated with male gender and not living alone. Overall loneliness was more strongly associated with emotional loneliness than social loneliness, while the correlation between emotional and social loneliness was weak and not statistically significant, allowing both types of loneliness to be entered into a generalised linear model as separate constructs.

\section{Main and interaction effects on quality of life}

In the fully adjusted model, significant main effects indicated that those who were female, had a long-term condition / disability, and had higher emotional or social loneliness, were associated with a lower quality of life (see Table 4).

A significant interaction was observed between 'long-term condition / disability' and 'sense of coherence' in relation to the outcome of 'quality of life'. Figure 3 demonstrates that a stronger sense of coherence buffered the negative effects of long-term condition / disability on quality of life.

\section{Discussion}

Some aspects of our a priori model were validated, whilst others were not. Model variables including age, gender, long-term condition / disability, living alone, providing more than 20 hours unpaid care for others per week, sense of coherence, overall loneliness, social loneliness and emotional loneliness, were strongly associated with quality of life, but perhaps surprisingly level of rurality was not. There are challenges in measuring rurality, as any approach inevitably averages households over a given geographical area and there may be subtle effects that have been overlooked by our current categorisation into three levels of rurality [22].

An interesting cluster of relationships identified in this study was the relationship between 'long-term condition / disability' with: age; living alone; overall loneliness; emotional loneliness; social loneliness; and a low sense of coherence. This is an extensive list of negative attributes, describing the huge challenges faced by an aging population who have a long-term condition / disability. Similarly, in our generalised linear model, a contributor to lower quality of life was long-term condition / disability.

Those with a high sense of coherence were less likely to have a either emotional or social loneliness. This is perhaps unsurprising, as salutogenesis proposes that 'general resistance resources' underpin a sense of coherence. Resistance resources include interpersonal-relational skills, which would be expected to lead to more extensive social networks and hence lower levels of loneliness [23].

The response rate, at $51.6 \%$, was reasonable for a survey of this nature, but still leaves the possibility of bias in relation to those who did not respond. A comparison of the characteristics of the survey population, the responding population, and the underlying sample frame, is provided in the Supplementary Material (Appendix 2), and provides some evidence that the respondents were representative of the population.

We note as a limitation that the six questions on loneliness were variably completed, perhaps because some participants appear to have thought that only some of the set of six loneliness questions needed to be answered. This misunderstanding may have arisen because each of the six loneliness questions did not have a specific question number assigned within the questionnaire, they were all clustered under one question number. There is potential learning for the way in which questions in a 
questionnaire are numbered that could be drawn from this study. As a result of missing data, some interpolation was undertaken, which should be noted as having some risk of bias associated with it, although our investigation of the issue indicates that it would have diluted any findings, and the risk of a Type 1 error, identifying an association that is not present, therefore appears to be relatively low. It can be argued that failure to address missing data would provide a greater risk of bias than the use of multiple interpolation.

This study is novel in examining the relationship between the presence of a long-term condition / disability and loneliness in an older rural population. The only comparably study identified was one which examined the relationship between loneliness and depressive symptoms in nursing homes, and demonstrated a relationship with resilience and social support, which is broadly consistent with some of the findings in this study [24].

A key question is what interventions can be put in place to address the needs of those with a long-term condition /disability in older populations, particularly where this is associated with living alone, and the associated risk of loneliness. Several reviews have identified a range of health promotion activities that can make a difference $[25,26]$. One study identified public sector savings of up to $£ 300$ per year for individuals receiving befriending support. Similarly, in selected groups, arts based community activities have been shown to significantly reduce the need for acute hospital care [27].

Given the aging nature of the population in many countries, viewed from a policy perspective, there is a growing need to understand interactions between different factors that affect the rising numbers of older people in the population who have a long term condition / disability. This study has sought to explore some of these factors in a rural context, and identified some important associations, which would benefit from being confirming in more longitudinal analyses.

\section{Declarations}

\section{Ethics approval and consent to participate}

Ethical approval was obtained from South Central - Oxford B Research Ethics Committee, reference 16/SC/0356. Consent was obtained as part of the survey form.

\section{Availability of data and materials}

The data set is availed from the corresponding author.

\section{Competing interests}

The corresponding author is an Associate Editor with BMC Public Health. Other authors have no competing interests to declare.

\section{Funding}

This study was largely funded by the NHS Highland. The National Institute of Health Research (NIHR) Oxford Biomedical Research Centre (BRC) have contributed to publication.

\section{Authors' contributions}

HvW conceived the study and led on drafting the paper; JL undertook the statistical analysis; all authors have read and agreed the final draft.

\section{Acknowledgements}

The authors wish to thanks staff in NHS Highland who supported the initial data collection within NHS Highland including: Sam Campbell, Barry Collard, Sharon Duncan, Sarah Griffin, Frances Hines, Elspeth Lee, Alison McGrory, Christine Robinson, Elisabeth Smart, Cathy Steer, Sara Huc, lan Douglas. 


\section{References}

1. Piccirillo JF, Vlahiotis A, Barrett LB, Flood KL, Spitznagel EL, Steyerberg EW: The changing prevalence of comorbidity across the age spectrum. Critical reviews in oncology/hematology 2008, 67(2):124-132.

2. Breheny M, Stephens C: Social policy and social identities for older people. The SAGE Handbook of Applied Social Psychology 2019:347.

3. Motl RW, McAuley E: Physical activity, disability, and quality of life in older adults. Physical Medicine and Rehabilitation Clinics 2010, 21(2):299-308.

4. Heyworth IT, Hazell ML, Linehan MF, Frank TL: How do common chronic conditions affect health-related quality of life? $\mathrm{Br}$ J Gen Pract 2009, 59(568):e353-e358.

5. Rees J, O'Boyle C, MacDonagh R: Quality of life: impact of chronic illness on the partner. Journal of the Royal Society of medicine 2001, 94(11):563-566.

6. Garcia MC, Faul M, Massetti G, Thomas CC, Hong Y, Bauer UE, lademarco MF: Reducing potentially excess deaths from the five leading causes of death in the rural United States. MMWR Surveillance Summaries 2017, 66(2):1.

7. Henning-Smith C, Moscovice I, Kozhimannil K: Differences in social isolation and its relationship to health by rurality. The Journal of Rural Health 2019.

8. Albrecht GL, Devlieger PJ: The disability paradox: high quality of life against all odds. Social science \& medicine 1999, 48(8):977-988

9. Sarvimäki A, Stenbock-Hult B: Quality of life in old age described as a sense of well-being, meaning and value. Journal of advanced nursing 2000, 32(4):1025-1033.

10. Lindström B, Eriksson M: Salutogenesis. Journal of Epidemiology \& Community Health 2005, 59(6):440-442.

11. Antonovsky A: Unraveling the mystery of health: How people manage stress and stay well. Sanfransisco, CA: Jossey-bass; 1987.

12. Antonovsky A: The structure and properties of the sense of coherence scale. Social science \& medicine 1993, 36(6):725733.

13. Your sense of coherence [https://psychcentral.com/lib/your-sense-of-coherence/]

14. Almedom AM: Resilience, hardiness, sense of coherence, and posttraumatic growth: All paths leading to "light at the end of the tunnel"? Journal of loss and trauma 2005, 10(3):253-265.

15. Eriksson M, Lindström B: Antonovsky's sense of coherence scale and the relation with health: a systematic review. Journal of epidemiology \& community health 2006, 60(5):376-381.

16. Hittner JB: Factorial invariance of the 13-item sense of coherence scale across gender. Journal of Health Psychology 2007, 12(2):273-280.

17. Schumann A, Hapke U, Meyer C, Rumpf HJ, John U: Measuring sense of coherence with only three items: a useful tool for population surveys. British journal of health psychology 2003, 8(4):409-421.

18. Defining Scotland by Rurality [https://www2.gov.scot/Topics/Statistics/About/Methodology/UrbanRuralClassification]

19. Gierveld JDJ, Tilburg TV: A 6-item scale for overall, emotional, and social loneliness: Confirmatory tests on survey data. Research on aging 2006, 28(5):582-598.

20. Lundberg O, Peck MN: A simplified way of measuring sense of coherence: experiences from a population survey in Sweden. The European Journal of Public Health 1995, 5(1):56-59.

21. Guyatt GH, Feeny DH, Patrick DL: Measuring health-related quality of life. Annals of Internal Medicine 1993, 118(8):622629.

22. Mountrakis G, AvRuskin G, Beard K: Modeling rurality using spatial indicators. In: Proceedings of the 8th International Conference on GeoComputation: 2005; 2005.

23. Langeland E, Wahl AK, Kristoffersen K, Hanestad BR: Promoting coping: salutogenesis among people with mental health problems. Issues in mental health nursing 2007, 28(3):275-295. 
24. Zhao X, Zhang D, Wu M, Yang Y, Xie H, Li Y, Jia J, Su Y: Loneliness and depression symptoms among the elderly in nursing homes: a moderated mediation model of resilience and social support. Psychiatry research 2018, 268:143-151.

25. Findlay RA: Interventions to reduce social isolation amongst older people: where is the evidence? Ageing \& Society 2003, 23(5):647-658.

26. Cattan $M$, White $M$, Bond J, Learmouth A: Preventing social isolation and loneliness among older people: a systematic review of health promotion interventions. Ageing \& Society 2005, 25(1):41-67.

27. Pitkala KH, Routasalo P, Kautiainen H, Tilvis RS: Effects of psychosocial group rehabilitation on health, use of health care services, and mortality of older persons suffering from loneliness: a randomized, controlled trial. Journals of Gerontology Series A: Biomedical Sciences and Medical Sciences 2009, 64(7):792-800.

\section{Tables}

Table 1: Descriptive statistics of participants' physical, environmental, and psychological characteristics, $\mathrm{N}=1471$

\begin{tabular}{|ll|}
\hline & $\%$ \\
\hline Physical & \\
Age groups & 29.7 \\
\hline $60-69$ & 47.3 \\
\hline $70-79$ & 23.0 \\
\hline $80+$ & 48.4 \\
\hline Male & 61.4 \\
\hline Long-term condition or disability & \\
Environmental & 21.5 \\
Rurality & 42.4 \\
\hline Other urban areas & 36.0 \\
\hline Small towns, accessible rural, and remote rural & 30.1 \\
\hline Very remote rural & 6.6 \\
\hline Living alone & \\
\hline Unpaid care for others 20+ hrs per week & 20.5 \\
Psychological & 46.8 \\
Sense of coherence & 32.7 \\
\hline Weak & 21.8 \\
\hline Intermediate & 17.2 \\
\hline Strong & 20.9 \\
\hline High levels of loneliness & $3.97[0.77]$ \\
\hline Overall & \\
\hline Emotional & \\
\hline Social & \\
\hline Quality of life; Mean [SD] & \\
\hline High determined by 1 SD above the mean & \\
\hline
\end{tabular}

Table 2: Bivariate associations of physical, environmental, and psychological variables with quality of life 


\begin{tabular}{|c|c|c|c|c|}
\hline & \multicolumn{2}{|c|}{ Quality of life } & \multicolumn{2}{|c|}{ ANOVA } \\
\hline & Mean & SD & F & $\mathbf{p}$ \\
\hline \multicolumn{4}{|l|}{ Age group } & \multirow{4}{*}{$<0.001$} \\
\hline $60-69$ & 4.12 & 0.72 & 22.67 & \\
\hline $70-79$ & 3.98 & 0.74 & & \\
\hline $80+$ & 3.75 & 0.83 & & \\
\hline \multicolumn{4}{|l|}{ Gender } & \multirow{3}{*}{$<0.001$} \\
\hline Female & 3.90 & 0.77 & 8.58 & \\
\hline Male & 4.05 & 0.75 & & \\
\hline \multicolumn{4}{|l|}{ Long-term condition / disability } & \multirow{3}{*}{$<0.001$} \\
\hline No & 4.26 & 0.74 & 143.35 & \\
\hline Yes & 3.79 & 0.70 & & \\
\hline \multicolumn{4}{|l|}{ Rurality } & \multirow{4}{*}{0.668} \\
\hline Other urban areas & 3.98 & 0.79 & 0.44 & \\
\hline Small towns, accessible rural, and remote rural & 3.98 & 0.76 & & \\
\hline Very remote rural & 3.95 & 0.76 & & \\
\hline \multicolumn{4}{|l|}{ Living alone } & \multirow{3}{*}{$<0.001$} \\
\hline Yes & 3.78 & 0.77 & 37.56 & \\
\hline No & 4.05 & 0.78 & & \\
\hline \multicolumn{4}{|l|}{ Unpaid care for others per week } & \multirow{3}{*}{$<0.001$} \\
\hline $0-<20$ hrs & 3.99 & 0.76 & 16.79 & \\
\hline $20 \mathrm{hrs}+$ & 3.66 & 0.77 & & \\
\hline \multicolumn{4}{|l|}{ Sense of coherence } & \multirow{4}{*}{$<0.001$} \\
\hline Weak & 3.31 & 0.79 & 246.41 & \\
\hline Intermediate & 3.96 & 0.65 & & \\
\hline Strong & 4.40 & 0.59 & & \\
\hline \multicolumn{4}{|l|}{ Overall loneliness $\dagger$} & \multirow{3}{*}{$<0.001$} \\
\hline Low & 4.08 & 0.75 & 175.11 & \\
\hline High & 3.48 & 0.74 & & \\
\hline \multicolumn{4}{|l|}{ Emotional loneliness } & \multirow{3}{*}{$<0.001$} \\
\hline Low & 4.09 & 0.75 & 212.97 & \\
\hline High & 3.36 & 0.73 & & \\
\hline \multicolumn{4}{|l|}{ Social loneliness } & \multirow{3}{*}{$<0.001$} \\
\hline Low & 4.10 & 0.76 & 195.60 & \\
\hline High & 3.46 & 0.74 & & \\
\hline
\end{tabular}

Table 3: Correlation matrix of physical, environmental, and psychological exposure variables 


\begin{tabular}{|c|c|c|c|c|c|c|c|c|c|c|}
\hline & Age & $\begin{array}{l}\text { Male } \\
\text { gender }\end{array}$ & $\begin{array}{l}\text { Long- } \\
\text { term } \\
\text { condition } \\
\text { / disability }\end{array}$ & Rurality & $\begin{array}{l}\text { Not } \\
\text { living } \\
\text { alone }\end{array}$ & $\begin{array}{l}\text { Unpaid } \\
\text { care } \\
\text { for } \\
\text { others } \\
20+ \\
\text { hrs per } \\
\text { week }\end{array}$ & $\begin{array}{l}\text { Overall } \\
\text { loneliness }\end{array}$ & $\begin{array}{l}\text { Emotional } \\
\text { loneliness }\end{array}$ & $\begin{array}{l}\text { Social } \\
\text { loneliness }\end{array}$ & $\begin{array}{l}\text { Sense of } \\
\text { coherence }\end{array}$ \\
\hline \multirow{10}{*}{$\begin{array}{l}\text { Age } \\
\text { Male } \\
\text { gender } \\
\text { Long- } \\
\text { term } \\
\text { condition } \\
\text { / } \\
\text { disability } \\
\text { Rurality } \\
\text { Not living } \\
\text { alone } \\
\text { Unpaid } \\
\text { care for } \\
\text { others } \\
\text { 20+ hrs } \\
\text { per week } \\
\text { Overall } \\
\text { loneliness } \\
\text { Emotional } \\
\text { loneliness } \\
\text { Social } \\
\text { loneliness } \\
\text { Sense of } \\
\text { coherence }\end{array}$} & 1.00 & & & & & & & & & \\
\hline & -.04 & 1.00 & & & & & & & & \\
\hline & $.16^{* *}$ & $.06 *$ & 1.00 & & & & & & & \\
\hline & -.01 & -.02 & -.02 & 1.00 & & & & & & \\
\hline & $-.16 * *$ & $.21 * *$ & $-.08 * *$ & $.10^{* *}$ & 1.00 & & & & & \\
\hline & -.01 & -.04 & -.01 & .02 & $.14^{* *}$ & 1.00 & & & & \\
\hline & .04 & $-.10 *$ & $.12^{* *}$ & -.01 & $-.17 *$ & .06 & 1.00 & & & \\
\hline & .07 & $-.12^{* *}$ & $.13 * *$ & -.03 & $-.21 * *$ & .02 & $.67 * *$ & 1.00 & & \\
\hline & -.01 & .00 & $.08^{* *}$ & .01 & $-.12^{* *}$ & $.09 *$ & .48 & .24 & 1.00 & \\
\hline & $-.11 * *$ & $.09 * *$ & $-.15^{* *}$ & -.01 & $.12 * *$ & $-.07 *$ & -.25 & $-.34 * *$ & $-.28 * *$ & 1.00 \\
\hline
\end{tabular}

Table 4: Generalized linear model on quality of life testing the main effects of physical, environmental, and psychological variables, and their interaction with sense of coherence

\begin{tabular}{|c|c|c|c|c|c|}
\hline & B & SE & lower & upper & $\mathbf{p}$ \\
\hline \multicolumn{6}{|l|}{ Main effects } \\
\hline Age & -0.08 & 0.05 & -0.17 & 0.01 & 0.075 \\
\hline Male gender* & 0.14 & 0.06 & 0.01 & 0.27 & 0.030 \\
\hline Long-term condition / disability*** & -0.44 & 0.07 & -0.57 & -0.31 & $<0.001$ \\
\hline Rurality & 0.02 & 0.04 & -0.07 & 0.10 & 0.705 \\
\hline Not living alone & 0.01 & 0.07 & -0.13 & 0.14 & 0.890 \\
\hline Unpaid care for others $20+$ hrs per week & -0.14 & 0.11 & -0.36 & 0.08 & 0.218 \\
\hline Emotional loneliness*** & -0.30 & 0.08 & -0.45 & -0.14 & $<0.001$ \\
\hline Social loneliness*** & -0.39 & 0.07 & -0.52 & -0.25 & $<0.001$ \\
\hline Sense of coherence & 0.40 & 0.27 & -0.12 & 0.92 & 0.134 \\
\hline \multicolumn{6}{|l|}{ Interaction with sense of coherence } \\
\hline Age & -0.01 & 0.03 & -0.08 & 0.06 & 0.775 \\
\hline Male gender & -0.05 & 0.05 & -0.15 & 0.04 & 0.279 \\
\hline Long-term condition / disability* & 0.10 & 0.05 & 0.01 & 0.20 & 0.037 \\
\hline Rurality & -0.04 & 0.03 & -0.11 & 0.03 & 0.268 \\
\hline Not living alone & 0.04 & 0.05 & -0.07 & 0.15 & 0.468 \\
\hline Unpaid care for others $20+$ hrs per week & -0.08 & 0.09 & -0.27 & 0.11 & 0.396 \\
\hline Emotional loneliness & 0.02 & 0.08 & -0.13 & 0.18 & 0.754 \\
\hline Social loneliness & 0.04 & 0.06 & -0.08 & 0.16 & 0.523 \\
\hline
\end{tabular}




\section{Figures}

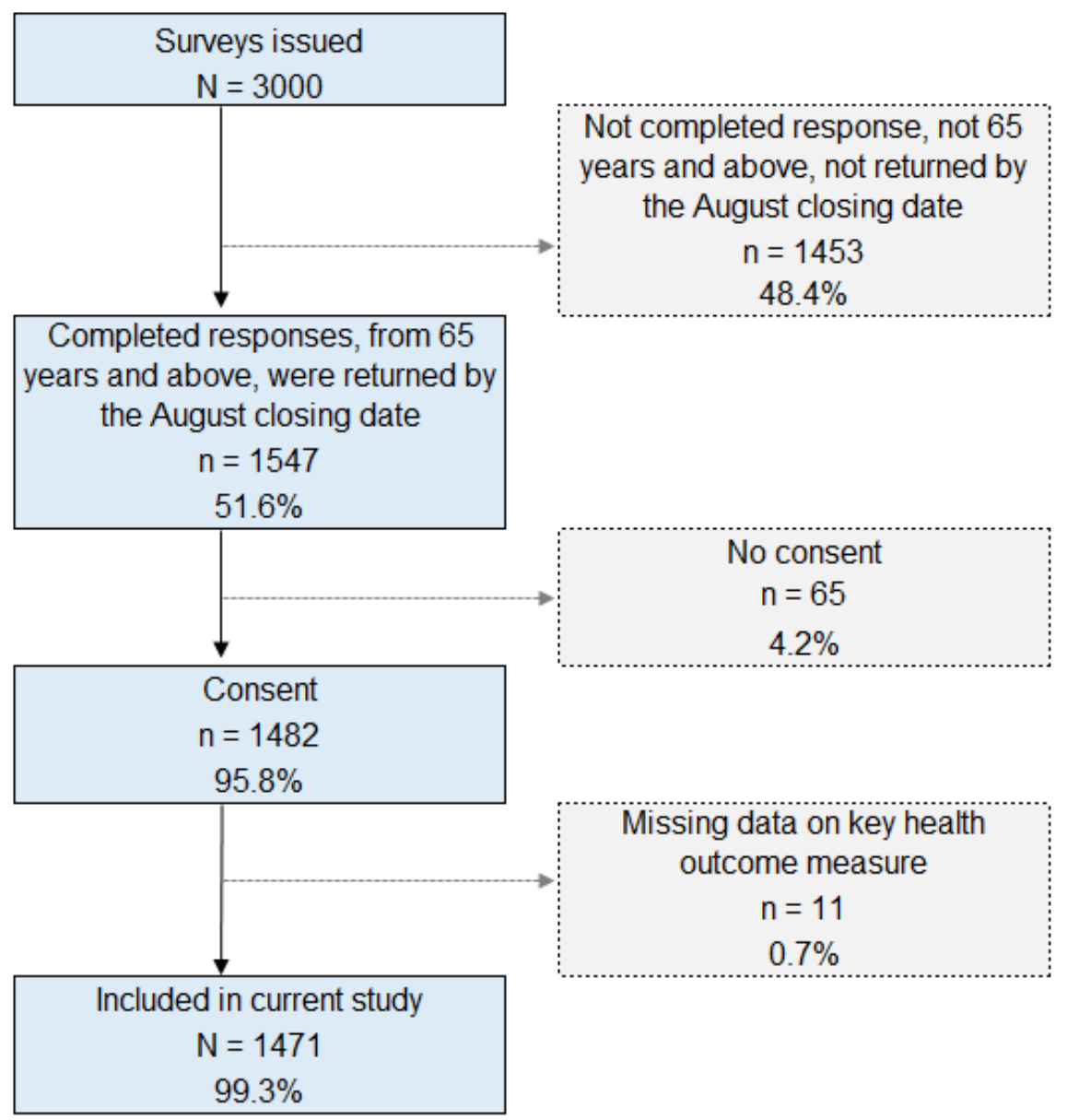

\section{Figure 1}

Conceptual model testing the moderation effects of sense of coherence on the relationship between physical, environmental, and psychological measures with quality of life 


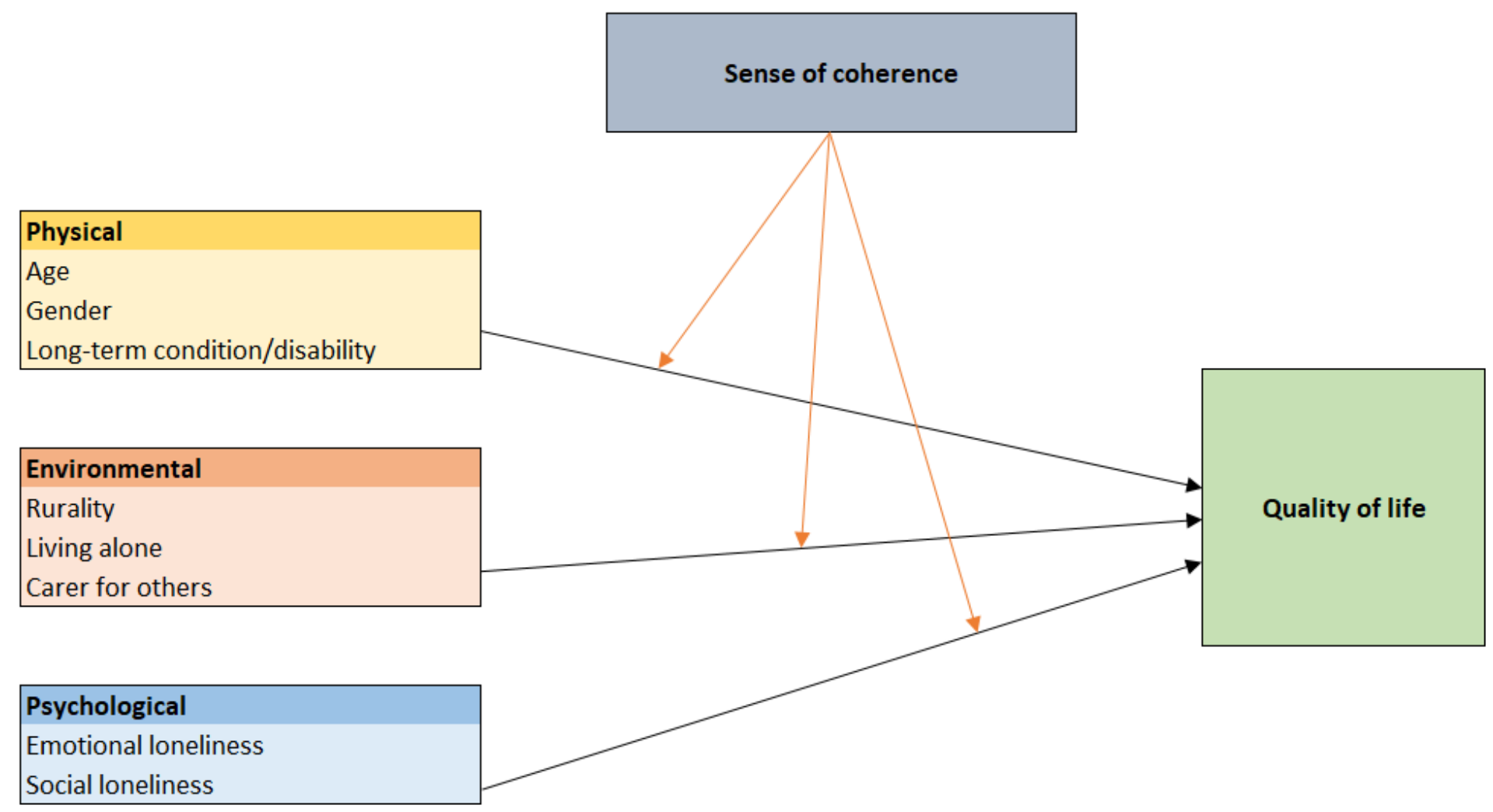

Figure 2

Flowchart of participants

5

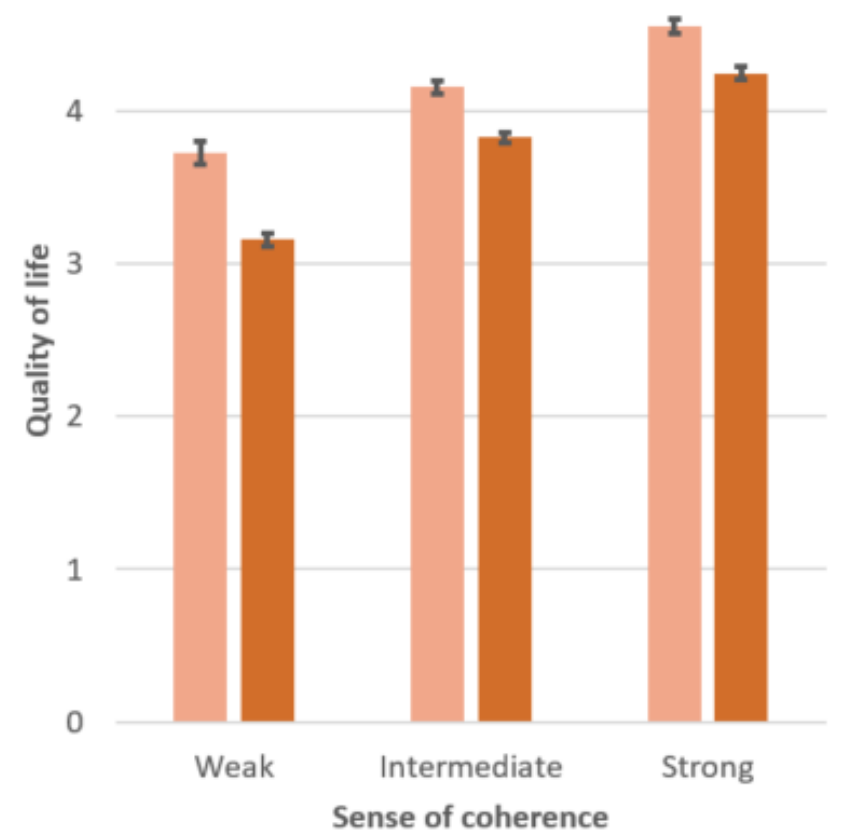

= No disability/condition = Long term disability / condition

Figure 3 
Buffering effects of sense of coherence on the relationship between long-term condition / disability with quality of life

\section{Supplementary Files}

This is a list of supplementary files associated with this preprint. Click to download.

- SupplementaryDataFile.docx 